Supporting Information for the Manuscript Entitled

\title{
Specific Interactions Improve the Payload Capacity of Block Copolymer Micelles in Aqueous Media
}

\author{
Cristiano Giacomelli, Vanessa Schmidt and Redouane Borsali* \\ Laboratoire de Chimie des Polymères Organiques (LCPO)-ENSCPB-Université Bordeaux 1, \\ 16 Av. Pey Berland, 33607 Pessac Cedex, France. \\ e-mail: borsali@enscpb.fr
}

* Present address: Centre de Recherche sur les Macromolécules Végétales (CERMAV), BP53, 38041, Grenoble Cedex 9, France.e-mail: borsali@cermav.cnrs.fr. 


\section{Synthesis of Amphiphilic Diblock Copolymers}

\subsection{Synthesis of PEO-based macroinitiadors for ATRP.}

In a typical procedure, ${ }^{1} \mathrm{CH}_{3} \mathrm{O}-\mathrm{PEO}_{113}-\mathrm{OH}(25.0 \mathrm{~g}, 5.0 \mathrm{mmol})$ was dissolved in $200 \mathrm{~mL}$ of dry toluene in a $500 \mathrm{~mL}$ three-neck flask. After azeotropic distillation of ca. $50 \mathrm{~mL}$ of toluene at reduced pressure to remove traces of water, dry triethylamine $(1.30 \mathrm{~mL}, 10.0 \mathrm{~mol})$ was added, and the solution was cooled down to $0{ }^{\circ} \mathrm{C}$. $\alpha$-Bromoisobutyryl bromide $(1.24 \mathrm{~mL}, 10.0 \mathrm{mmol})$ was added dropwise via syringe, and the reaction mixture was stirred overnight at room temperature. The stirred solution was treated with charcoal, which was subsequently removed by filtration, and most of the toluene was removed by rotary evaporation prior to precipitation into a 10-fold excess of ether. The crude polymer re-dissolved in $200 \mathrm{~mL}$ of $\mathrm{CH}_{2} \mathrm{Cl}_{2}$, and then extracted with $\mathrm{K}_{2} \mathrm{CO}_{3}$ saturated aqueous solution ( $3 \times 200 \mathrm{~mL}$ ). The organic phase was dried over $\mathrm{MgSO}_{4}$, and the final bromo-terminated PEO was obtained after re-precipitation in ether. Pure white products were obtained after three times precipitation in cold diethyl ether. ${ }^{1} \mathrm{H}$ NMR analysis (not shown) indicated quantitative substitution of hydroxyl end groups.

\subsection{Synthesis of PEO-b-PDPA}

In a typical ATRP procedure, DPA monomer $(3.0 \mathrm{~mL}, 12.8 \mathrm{mmol})$, HMTETA ligand $(0.15 \mathrm{~mL}$, $0.54 \mathrm{mmol})$, and distilled THF as solvent $(6.0 \mathrm{~mL})$ were charged into a dry $100 \mathrm{~mL}$ Schlenk flask. The tube was sealed with a rubber septum and subjected to four freeze-pump-thaw cycles, then the solution was cannulated under nitrogen into another Schlenk tube, previously evacuated and filled with nitrogen, containing $\mathrm{Cu}(\mathrm{I}) \mathrm{Br}(0.04 \mathrm{~g}, 0.27 \mathrm{mmol}), \mathrm{PEO}_{113}-\mathrm{Br}$ macroinitiator (1.36 g, 0.27 mmol), and a magnetic stirrer. The solution was then immediately immersed in an oil bath at $60^{\circ} \mathrm{C}$ to start the polymerization. After $180 \mathrm{~min},{ }^{1} \mathrm{H}$ NMR analysis indicated that $95 \%$ of DPA had been polymerized. The reaction was then stopped by cooling down, opening the flask to air and adding 50 $\mathrm{mL}$ of aerated THF. The mixture was subsequently passed through a basic alumina column in order to remove the spent ATRP catalyst. The final product was obtained after evaporation of volatiles and precipitation in pentane.

The characteristics of PEO- $b$-PDPA diblocks used in this work are summarized in Table S1. 
Table S1. Characteristics of PEO- $b$-PDPA diblock copolymers.

\begin{tabular}{|c|c|c|c|c|c|c|}
\hline $\begin{array}{c}\text { Diblock } \\
\text { Copolymer }\end{array}$ & $\begin{array}{l}\text { time } \\
\text { (h) }\end{array}$ & $\begin{array}{c}\text { Conv. }^{\mathrm{a}} \\
(\%)\end{array}$ & $\begin{array}{c}\mathrm{M}_{\mathrm{n}}(\text { target })^{\mathrm{b}} \\
\mathrm{g} / \mathrm{mol}\end{array}$ & $\begin{array}{c}\mathrm{M}_{\mathrm{n}}(\mathrm{NMR})^{\mathrm{c}} \\
\mathrm{g} / \mathrm{mol}\end{array}$ & $\begin{array}{c}\mathrm{M}_{\mathrm{n}} \\
(\mathrm{GPC})^{\mathrm{d}} \\
\mathrm{g} / \mathrm{mol}\end{array}$ & $\mathrm{M}_{\mathrm{w}} / \mathrm{M}_{\mathrm{n}}{ }^{\mathrm{d}}$ \\
\hline $\begin{array}{l}\mathrm{PEO}_{113}-b- \\
\mathrm{PDPA}_{12}\end{array}$ & 1.0 & 93 & 8,000 & 7,600 & 9,800 & 1.18 \\
\hline $\begin{array}{l}\mathrm{PEO}_{113}-b- \\
\mathrm{PDPA}_{50}\end{array}$ & 3.0 & 95 & 15,000 & 15,700 & 15,300 & 1.15 \\
\hline
\end{tabular}

\subsection{Synthesis of PEO-b-PGMA}

The synthesis of PEO- $b$-PGMA diblock copolymers was performed applying essentially the same ATRP protocol as described above. In this case, however, the polymerization was carried out in DPE at $30{ }^{\circ} \mathrm{C}$ in presence of $\mathrm{Cu}(\mathrm{I}) \mathrm{Br} / \mathrm{PMDETA}$ as catalyst. ${ }^{2}$ The final product was obtained after precipitation in heptane. The characteristics of PEO- $b$-PGMA diblocks used in this work are summarized in Table S2.

Table S2. Characteristics of PEO- $b$-PGMA diblock copolymer.

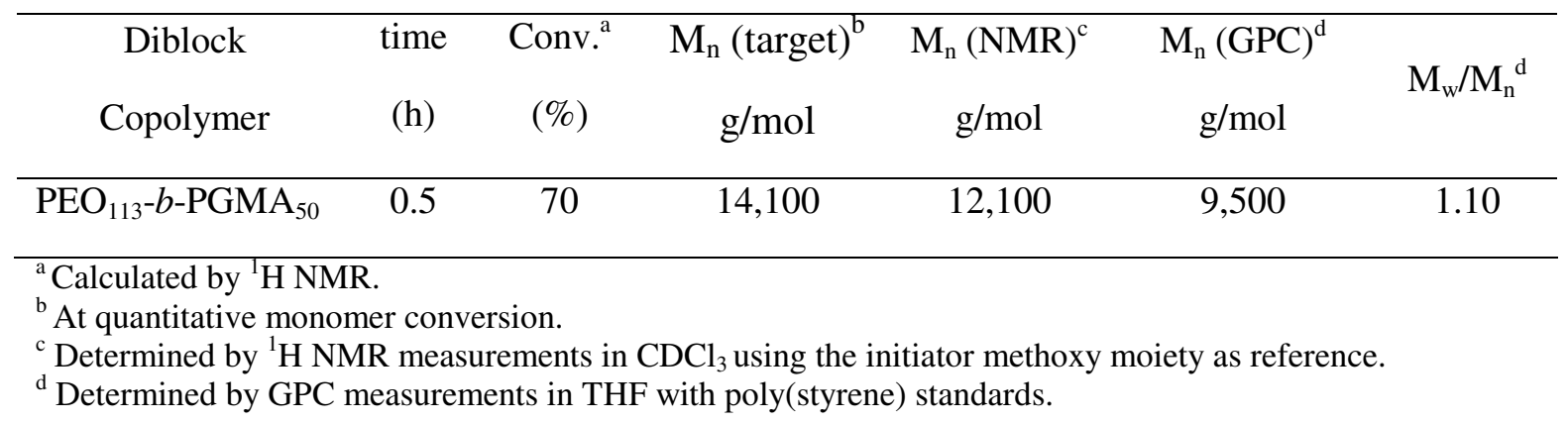

\subsection{Synthesis of PG2MA-b-PDPA}

The synthesis of PG2MA- $b$-PDPA diblock copolymers was carried out via sequential monomer addition using ATRP protocols. ${ }^{3}$ Briefly, G2MA monomer $(5.75 \mathrm{~g}, 36 \mathrm{mmol})$ and methanol as solvent $(6.0 \mathrm{~mL})$ were charged to a dry $100 \mathrm{~mL}$ Schlenk flask. After purging with nitrogen during 30 min to remove dissolved oxygen, the solution was cannulated under nitrogen into another Schlenk tube, previously evacuated and filled with nitrogen, containing $\mathrm{Cu}(\mathrm{I}) \mathrm{Br}(0.13 \mathrm{~g}, 0.90 \mathrm{mmol}),(\mathrm{OH})_{2^{-}}$ 
SK-Br (1-O-(2'-bromo-2'-methylpropionoyl)-2,3-rac-glycerol $)^{4}$ initiator (0.22 g, $\left.0.90 \mathrm{mmol}\right), 2,2^{\prime}$ bipyridyl (bpy) ligand $(0.28 \mathrm{~g}, 1.80 \mathrm{mmol})$, and a magnetic stirrer. The reaction mixture became immediately dark brown and progressively more viscous, indicating the onset of polymerization. The polymerization was allowed to continue for approximately $2 \mathrm{~h}$, at which point the monomer conversion was virtually complete as indicted by ${ }^{1} \mathrm{H}$ NMR. The required amount of DPA monomer was then added to this reaction solution and ${ }^{1} \mathrm{H}$ NMR used to monitor the reaction until monomer consumption was again complete (typically within $7 \mathrm{~h}$ at $20^{\circ} \mathrm{C}$ ). The reaction solutions were treated with silica gel to remove the ATRP catalyst, and precipitated in to remove any traces of residual DPA monomer. The final white product was thus obtained after being vacuum dried overnight. The characteristics of the resulting copolymers are summarized in Table S3.

Table S3. Characteristics of PG2MA- $b$-PDPA diblock copolymer.

\begin{tabular}{ccccc}
\hline $\begin{array}{c}\text { Diblock } \\
\text { Copolymer }\end{array}$ & $\begin{array}{c}\mathrm{M}_{\mathrm{n}} \text { (target }^{\mathrm{a}}{ }^{2} \\
\mathrm{~g} / \mathrm{mol}\end{array}$ & $\begin{array}{c}\mathrm{M}_{\mathrm{n}}(\mathrm{NMR})^{\mathrm{b}} \\
\mathrm{g} / \mathrm{mol}\end{array}$ & $\begin{array}{c}\mathrm{M}_{\mathrm{n}}(\mathrm{GPC})^{\mathrm{c}} \\
\mathrm{g} / \mathrm{mol}\end{array}$ & $\mathrm{M}_{\mathrm{w}} / \mathrm{M}_{\mathrm{n}}{ }^{\mathrm{c}}$ \\
\hline PG2MA $_{40}-b-\mathrm{PDPA}_{15}$ & 13,600 & 9,600 & 14,300 & 1.17 \\
\hline & & & & \\
\hline
\end{tabular}

\section{Determination of Drug Loading Content in the Micelles}

The probe content effectively encapsulated inside the micellar nano-carriers was determined by UV-vis spectrometry using analytical curves obtained at probe concentrations ranging from 5.0 to $100.0 \mu \mathrm{g} / \mathrm{mL}$ in THF (or ethanol). In all cases, the UV-vis absorption intensity at $\lambda_{\max }$ depended linearly on the concentration, as illustrated in Figure S1 for Indomethacin morpholinylamide (IND-M).

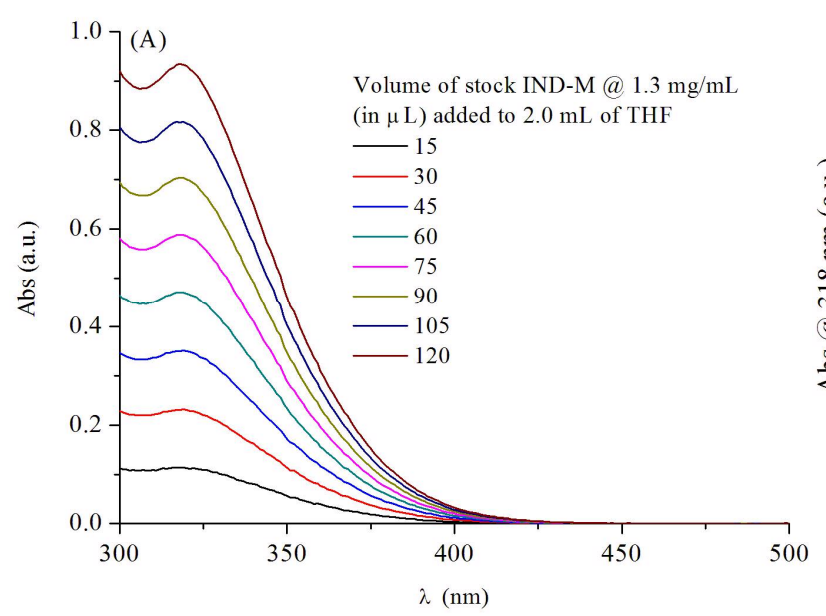


Figure S1. UV-vis absorption spectra acquired as a function of known added aliquots of $1.3 \mathrm{mg} / \mathrm{mL}$ IND-M in THF (a), and the respective analytical curve (b). 


\section{References}

1. Liu, S.; Weaver, J. V. M.; Tang, Y.; Billingham, N. C.; Armes, S. P.; Tribe, K. Macromolecules 2002, 35, (16), 6121-6131.

2. Cañamero, P. F.; Fuente, J. F.; Madruga, E. L.; Fernández-García, M. Macromol. Chem. Phys. 2004, 205, (16), 2221-2228.

3. Fujii, S.; Cai, Y.; Weaver, J. V. M.; Armes, S. P. J. Am. Chem. Soc. 2005, 127, (20), 73047305.

4. Lecolley, F. New Polymers from Living Radical Polymerisation for Biological Applications. PhD thesis, University of Warwick, Warwick, 2004. 